\title{
Coupled Coincidence And Common Fixed Point Theorems For Mappings In Partially Ordered Metric Spaces
}

\author{
R. Arab*, A.Godarzian \\ Department Of Mathematics, Sari Branch, Islamic Azad University, Sari, Iran \\ * E-mail of the corresponding author: mathreza.arab @iausari.ac.ir, \\ mathreza.arab@yahoo.com
}

\begin{abstract}
In this paper, we prove coupled coincidence points and common fixed points theorem for two mappings satisfying various contractive conditions in partially ordered metric spaces. Our results will generalize and extend some recent results in fixed point theory.

Keywords: Common Fixed Point, Coupled Fixed Point, Coupled Coincidence Point, Mixed $g$-Monotone Property, Partially Ordered Set.
\end{abstract}

\section{Introduction and Preliminaries}

Throughout this article, unless otherwise specified, we always suppose that $\mathbb{N}$ is the set of positive integers and $X$ is a non empty set. Some authors generalized the Banach contraction principle theorem [2] in different ways. Recently, Bhashkar and Lakshmikantham[3] expressed coupled coincidence points, coupled fixed points, coupled common fixed points and common fixed points of nonlinear mappings with two variables. After publication of this work, several coupled fixed point and coincidence point results have appeared in the recent literature. Works noted in $[1,4,5,6,7,8,9,10,11]$ are some relevant examples. The aim of this article is to make further studies on such problems, and to generalize and complement some known results. Next, let us recall some related definitions:

Definition 1.1 [3] Let $(X, \preceq)$ be a partially ordered set, and $F: X \times X \rightarrow X$. The mapping $F$ has the mixed monotone property if $F(x, y)$ is monotone non-decreasing in $x$ and is monotone non-increasing in y.

Definition 1.2 [3] An element $(x, y) \in X \times X$ is called a coupled fixed point of the mapping $F: X \times X \rightarrow X$ if $F(x, y)=x, F(y, x)=y$.

The main results of Bhaskar and Lakshmikantham in [3] are the following coupled fixed point theorems.

Theorem 1.1 [3] Let $(X, \preceq)$ be a partially ordered set and suppose there exists a metric $d$ on $X$ such that $(X, d)$ is a complete metric space. Let $F: X \times X \rightarrow X$ be a continuous mapping having the mixed monotone property on $X$. Assume that there exists a $k \in[0,1)$ with

$$
d(F(x, y), F(u, v)) \leq \frac{k}{2}[d(x, u)+d(y, v)]
$$

for all $u \preceq x$ and $y \preceq v$. If there exist two elements $x_{0}, y_{0} \in X$ with $x_{0} \preceq F\left(x_{0}, y_{0}\right)$ and 
$F\left(y_{0}, x_{0}\right) \preceq y_{0}$, then $F$ has a coupled fixed point.

Recently, R. Bhardwaj [4] proved some generalizations of the main results in [3].

Theorem 1.2 [4] Let $(X, d, \preceq)$ be a partially ordered complete metric space. Suppose there exist $\lambda \in[0,1)$, $T: X \times X \rightarrow X$ such that

$$
\begin{aligned}
& d(T(x, y), T(u, v)) \leq \lambda \max \left\{\frac{d(x, T(x, y)) \cdot d(u, T(u, v))}{d(x, u)}, \frac{d(u, T(x, y)) \cdot d(x, T(u, v))}{d(x, u)}\right. \\
& , d(x, u)\}
\end{aligned}
$$

for all $x, y, u, v \in X$ with $x \preceq u, y \succeq v$ and $x \neq u$. Suppose also that $T$ is continuous, has the mixed monotone property on $X$. If there exist $\left(x_{0}, y_{0}\right) \in X \times X$ such that $x_{0} \preceq T\left(x_{0}, y_{0}\right)$ and $y_{0} \succeq T\left(y_{0}, x_{0}\right)$, then there exist $x, y \in X$ such that $x=T(x, y)$ and $y=T(y, x)$.

In [7], Lakshmikantham and $C^{\prime}{ }^{\prime}$ ric $^{\prime}$ introduced the concept of mixed $g$-monotone property which present these definitions and results in the following.

Definition 1.3 [7] Let $(X, \preceq)$ be a partially ordered set, and $F: X \times X \rightarrow X$ and $g: X \rightarrow X$. We say $F$ has the mixed $g$-monotone property if $F$ is nondecreasing $g$-monotone in its first argument and is nondecreasing $g$-monotone in its second argument, that is, for any $x, y \in X$

$$
x_{1}, x_{2} \in X, g x_{1} \preceq g x_{2} \Rightarrow F\left(x_{1}, y\right) \preceq F\left(x_{2}, y\right)
$$

and

$$
y_{1}, y_{2} \in X, g y_{1} \preceq g y_{2} \Rightarrow F\left(x, y_{1}\right) \succeq F\left(x, y_{2}\right) .
$$

Note that if $g$ is the identity mapping, then Definition 1.4 reduces to Definition 1.2 .

Definition 1.4 [7] An element $(x, y) \in X \times X$ is called a coupled coincidence point of a mapping $F: X \times X \rightarrow X$ and a mapping $g: X \rightarrow X$ if $F(x, y)=g x, F(y, x)=g y$.

Definition 1.5 [7] An element $x \in X$ is called a common fixed point of a mapping $F: X \times X \rightarrow X$ and $g: X \rightarrow X$ if $F(x, x)=g x=x$.

Definition 1.6 [7] Let $X$ be a nonempty set and $F: X \times X \rightarrow X$ and $g: X \rightarrow X$. One says $F$ and $g$ are commutative if for all $x, y \in X, F(g x, g y)=g(F(x, y))$.

\section{Main results}


Our first result is the following.

Theorem 2.1 Let $(X, d, \preceq)$ be a partially ordered complete metric space. Let $T: X \times X \rightarrow X$, $g: X \rightarrow X$ and $\phi, \psi:[0, \infty) \rightarrow[0, \infty)$ satisfy following condition

$\psi(d(T(x, y), T(u, v))) \leq \psi(M(x, y, u, v))-\phi(M(x, y, u, v))$,

for all $x, y, u, v \in X$ with $g x \preceq g u, g y \succeq g v$ and $g x \neq g u$, where $\phi$ is lower semi-continuous, $\psi$ is continuous, non-decreasing, $\phi(t)=0=\psi(t)$ if and only if $t=0$ and $M(x, y, u, v)=\max \left\{\frac{d(g x, T(x, y)) \cdot d(g u, T(u, v))}{d(g x, g u)}, \frac{d(g u, T(x, y)) \cdot d(g x, T(u, v))}{d(g x, g u)}, d(g x, g u)\right\}$.

Also, assume $T$ and $g$ are continuous mappings such that $T$ has the mixed $g$-monotone property, $g$ commutes with $T$ and $T(X \times X) \subseteq g(X)$. If there exists $\left(x_{0}, y_{0}\right) \in X \times X \quad$ such that $g x_{0} \preceq T\left(x_{0}, y_{0}\right)$ and $g y_{0} \succeq T\left(y_{0}, x_{0}\right)$, then $T$ and $g$ have coupled coincidence point in $X$.

Proof. By the condition of the theorem there exist $\left(x_{0}, y_{0}\right) \in X \times X$ such that $g x_{0} \preceq T\left(x_{0}, y_{0}\right)$ and $g y_{0} \succeq T\left(y_{0}, x_{0}\right)$. Since $T(X \times X) \subseteq g(X)$, we can define $\quad\left(x_{1}, y_{1}\right) \in X \times X \quad$ such that $g x_{1}=T\left(x_{0}, y_{0}\right) \quad$ and $\quad g y_{1}=T\left(y_{0}, x_{0}\right), \quad$ then $\quad g x_{0} \preceq T\left(x_{0}, y_{0}\right)=g x_{1} \quad$ and $\quad g y_{0} \succeq T\left(y_{0}, x_{0}\right)=g y_{1}$.

Since $T$ has the mixed $g$-monotone property, we have

$$
g x_{1}=T\left(x_{0}, y_{0}\right) \preceq T\left(x_{0}, y_{1}\right) \preceq T\left(x_{1}, y_{1}\right)=g x_{2},
$$

and

$$
g y_{2}=T\left(y_{1}, x_{1}\right) \preceq T\left(y_{0}, x_{1}\right) \preceq T\left(y_{0}, x_{0}\right)=g y_{1} .
$$

Continuing in this way, we construct two sequences $\left\{x_{n}\right\}$ and $\left\{y_{n}\right\}$ in $X$ such that

$$
g x_{n+1}=T\left(x_{n}, y_{n}\right) \text { and } g y_{n+1}=T\left(y_{n}, x_{n}\right) \text { for all } n=0,1,2, \ldots
$$

for which

$$
g x_{0} \preceq g x_{1} \preceq g x_{2} \preceq \ldots \preceq g x_{n} \preceq g x_{n+1} \preceq \ldots \text { and } \quad g y_{0} \succeq g y_{1} \succeq g y_{2} \succeq \ldots \succeq g y_{n} \succeq g y_{n+1} \succeq \ldots .
$$

If there exists $k_{0} \in \mathbb{N}$ such that $g x_{k_{0}+1}=g x_{k_{0}}$ and $g y_{k_{0}+1}=g y_{k_{0}}$, then $g x_{k_{0}}=T\left(x_{k_{0}}, y_{k_{0}}\right)$ and 
$g y_{k_{0}}=T\left(y_{k_{0}}, x_{k_{0}}\right)$. This means that $\left(x_{k_{0}}, y_{k_{0}}\right)$ is a coupled coincidence point of $T, g$ and the proof is finished. Thus, we can suppose that $g x_{n+1} \neq g x_{n}$ and $g y_{n+1} \neq g y_{n}$ for all $n \in \mathbb{N}$. From (2.2) and

(2.3) and the inequality (2.1) with $(x, y)=\left(x_{n}, y_{n}\right)$ and $(u, v)=\left(x_{n+1}, y_{n+1}\right)$, we have

$$
\begin{aligned}
\psi\left(d\left(g x_{n+1}, g x_{n+2}\right)\right) & =\psi\left(d\left(T\left(x_{n}, y_{n}\right), T\left(x_{n+1}, y_{n+1}\right)\right)\right) \\
& \leq \psi\left(M\left(x_{n}, y_{n}, x_{n+1}, y_{n+1}\right)\right)-\phi\left(M\left(x_{n}, y_{n}, x_{n+1}, y_{n+1}\right)\right)
\end{aligned}
$$

where

$$
\begin{aligned}
& M\left(x_{n}, y_{n}, x_{n+1}, y_{n+1}\right)=\max \left\{\frac{d\left(g x_{n}, T\left(x_{n}, y_{n}\right)\right) \cdot d\left(g x_{n+1}, T\left(x_{n+1}, y_{n+1}\right)\right)}{d\left(g x_{n}, g x_{n+1}\right)},\right. \\
& \left.\frac{d\left(g x_{n+1}, T\left(x_{n}, y_{n}\right)\right) \cdot d\left(g x_{n}, T\left(x_{n+1}, y_{n+1}\right)\right)}{d\left(g x_{n}, g x_{n+1}\right)}, d\left(g x_{n}, g x_{n+1}\right)\right\} \\
& =\max \left\{\frac{d\left(g x_{n}, g x_{n+1}\right) \cdot d\left(g x_{n+1}, g x_{n+2}\right)}{d\left(g x_{n}, g x_{n+1}\right)}, \frac{d\left(g x_{n+1}, g x_{n+1}\right) \cdot d\left(g x_{n}, g x_{n+2}\right)}{d\left(g x_{n}, g x_{n+1}\right)}, d\left(g x_{n}, g x_{n+1}\right)\right\} \\
& =\max \left\{d\left(g x_{n+1}, g x_{n+2}\right), d\left(g x_{n}, g x_{n+1}\right)\right\} .
\end{aligned}
$$

Therefore

$$
\begin{aligned}
\psi\left(d\left(g x_{n+1}, g x_{n+2}\right)\right) \leq \psi & \left(\max _{\{}\left\{\left(g x_{n}, g x_{n+1}\right), d\left(g x_{n+1}, g x_{n+2}\right)\right\}\right) \\
& -\phi\left(\max _{2}\left\{d\left(g x_{n}, g x_{n+1}\right), d\left(g x_{n+1}, g x_{n+2}\right)\right\}\right) .
\end{aligned}
$$

We prove that for all $n \in \mathbb{N}$,

$$
d\left(g x_{n+1}, g x_{n+2}\right) \leq d\left(g x_{n}, g x_{n+1}\right) .
$$

Suppose there exists $n_{0} \in \mathbb{N}$ such that $d\left(g x_{n_{0}+1}, g x_{n_{0}+2}\right)>d\left(g x_{n_{0}}, g x_{n_{0}+1}\right)$, from (2.5), we have

$$
\begin{aligned}
& \psi\left(d\left(g x_{n_{0}+1}, g x_{n_{0}+2}\right)\right) \leq \psi(\left.\max \left\{d\left(g x_{n_{0}}, g x_{n_{0}+1}\right), d\left(g x_{n_{0}+1}, g x_{n_{0}+2}\right)\right\}\right) \\
&-\phi\left(\max \left\{d\left(g x_{n_{0}}, g x_{n_{0}+1}\right), d\left(g x_{n_{0}+1}, g x_{n_{0}+2}\right)\right\}\right) \\
&=\psi\left(d\left(g x_{n_{0}+1}, g x_{n_{0}+2}\right)\right)-\phi\left(d\left(g x_{n_{0}+1}, g x_{n_{0}+2}\right)\right)<\psi\left(d\left(g x_{n_{0}+1}, g x_{n_{0}+2}\right)\right),
\end{aligned}
$$

which is a contradiction. Hence, $d\left(g x_{n+1}, g x_{n+2}\right) \leq d\left(g x_{n}, g x_{n+1}\right)$ for all $n \in \mathbb{N}$.

Similarly, we can show that $d\left(g y_{n+1}, g y_{n+2}\right) \leq d\left(g y_{n}, g y_{n+1}\right)$ for all $n \in \mathbb{N}$.

It follows that the sequences $\left\{d\left(g x_{n}, g x_{n+1}\right)\right\}$ and $\left\{d\left(g y_{n}, g y_{n+1}\right)\right\}$ are monotone decreasing sequences of non-negative real numbers and consequently there exists $\delta_{1}, \delta_{2} \geq 0$ such that

$$
\lim _{n \rightarrow \infty} d\left(g x_{n}, g x_{n+1}\right)=\delta_{1} \text { and } \lim _{n \rightarrow \infty} d\left(g y_{n}, g y_{n+1}\right)=\delta_{2} .
$$

We shall show that $\delta_{1}=\delta_{2}=0$. Suppose, to the contrary, that $\delta_{1}>0$. 
Taking the (upper) limit as $n \rightarrow \infty$ in (2.5) and using the properties of the function $\phi$, we get

$$
\psi\left(\delta_{1}\right) \leq \psi\left(\delta_{1}\right)-\liminf _{n \rightarrow \infty} \phi\left(\delta_{1}\right) \leq \psi\left(\delta_{1}\right)-\phi\left(\delta_{1}\right)<\psi\left(\delta_{1}\right)
$$

which is a contradiction. Therefore, $\delta_{1}=0$, that is,

$$
\lim _{n \rightarrow \infty} d\left(g x_{n}, g x_{n+1}\right)=0 .
$$

Similarly, we can show that

$$
\lim _{n \rightarrow \infty} d\left(g y_{n}, g y_{n+1}\right)=0 .
$$

Now, we claim that

$$
\lim _{n, m \rightarrow \infty} d\left(g x_{n}, g x_{m}\right)=0 .
$$

Assume the contrary. Then there exists $\varepsilon>0$ for which we can find two subsequences $\left\{g x_{m(k)}\right\},\left\{g x_{n(k)}\right\}$ of $\left\{g x_{n}\right\}$ with $m(k)>n(k) \geq k$ such that

$$
d\left(g x_{n(k)}, g x_{m(k)}\right) \geq \varepsilon
$$

Additionally, corresponding to $n(k)$, we may choose $m(k)$ such that it is the smallest integer satisfying (2.11) and $m(k)>n(k) \geq k$. Thus,

$$
d\left(g x_{n(k)}, g x_{m(k)-1}\right)<\varepsilon
$$

We have

$\varepsilon \leq d\left(g x_{m(k)}, g x_{n(k)}\right) \leq d\left(g x_{m(k)}, g x_{m(k)-1}\right)+d\left(g x_{m(k)-1}, g x_{n(k)}\right)<d\left(g x_{m(k)}, g x_{m(k)-1}\right)+\varepsilon$.

Taking the upper limit as $k \rightarrow \infty$ and using (2.8) we obtain

$$
\lim _{k \rightarrow \infty} d\left(g x_{n(k)}, g x_{m(k)}\right)=\varepsilon
$$

Also

$$
\begin{aligned}
& d\left(g x_{m(k)-1}, g x_{n(k)-1}\right) \leq d\left(g x_{m(k)-1}, g x_{m(k)}\right)+d\left(g x_{m(k)}, g x_{n(k)}\right)+d\left(g x_{n(k)}, g x_{n(k)-1}\right), \\
& d\left(g x_{n(k)-1}, g x_{m(k)}\right) \leq d\left(g x_{n(k)-1}, g x_{n(k)}\right)+d\left(g x_{n(k)}, g x_{m(k)}\right), \\
& d\left(g x_{m(k)}, g x_{n(k)}\right) \leq d\left(g x_{m(k)}, g x_{n(k)-1}\right)+d\left(g x_{n(k)-1}, g x_{n(k)}\right), \\
& d\left(g x_{n(k)}, g x_{m(k)}\right) \leq d\left(g x_{m(k)}, g x_{m(k)-1}\right)+d\left(g x_{m(k)-1}, g x_{n(k)-1}\right)+d\left(g x_{n(k)-1}, g x_{n(k)}\right) .
\end{aligned}
$$

So from $(2.8),(2.13)$ and taking $k \rightarrow \infty$ in the above inequalities, we have

$$
\lim _{k \rightarrow \infty} d\left(g x_{n(k)-1}, g x_{m(k)-1}\right)=\lim _{k \rightarrow \infty} d\left(g x_{n(k)-1}, g x_{m(k)}\right)=\varepsilon .
$$


Also

$$
d\left(g x_{m(k)-1}, g x_{n(k)-1}\right) \leq d\left(g x_{m(k)-1}, g x_{n(k)}\right)+d\left(g x_{n(k)}, g x_{n(k)-1}\right)<\varepsilon+d\left(g x_{n(k)}, g x_{n(k)-1}\right)
$$

So from $(2.8),(2.14)$ and taking $k \rightarrow \infty$ in the above inequalities, we have

$$
\lim _{k \rightarrow \infty} d\left(g x_{n(k)}, g x_{m(k)-1}\right)=\varepsilon .
$$

By the definition of $M(x, y, u, v)$ and from (2.8), (2.14) and (2.15) we get

$$
\lim _{k \rightarrow \infty} M\left(x_{n(k)-1}, y_{n(k)-1}, x_{m(k)-1}, y_{m(k)-1}\right)=\varepsilon .
$$

Since $m(k)>n(k), g x_{m(k)-1} \succeq g x_{n(k)-1}$ and $g y_{m(k)-1} \preceq g y_{n(k)-1}$ from (2.1), we have

$$
\begin{aligned}
& \psi\left(d\left(g x_{m(k)}, g x_{n(k)}\right)\right)=\psi\left(d\left(T\left(x_{n(k)-1}, y_{n(k)-1}\right), T\left(x_{m(k)-1}, y_{m(k)-1}\right)\right)\right. \\
& \leq \psi\left(M\left(x_{n(k)-1}, y_{n(k)-1}, x_{m(k)-1}, y_{m(k)-1}\right)\right)-\phi\left(M\left(x_{n(k)-1}, y_{n(k)-1}, x_{m(k)-1}, y_{m(k)-1}\right)\right),
\end{aligned}
$$

Taking the upper limit as $k \rightarrow \infty$, and using (2.16), we obtain

$$
\psi(\varepsilon) \leq \psi(\varepsilon)-\phi(\varepsilon)<\psi(\varepsilon)
$$

which is a contradiction. Therefore (2.10) holds, and we have

$$
\lim _{n, m \rightarrow \infty} d\left(g x_{n}, g x_{m}\right)=0 .
$$

Similarly, we show that

$$
\lim _{n, m \rightarrow \infty} d\left(g y_{n}, g y_{m}\right)=0 .
$$

Since $X$ is a complete metric space, there exist $x, y \in X$ such that

$$
\lim _{n \rightarrow \infty} g x_{n+1}=x \text { and } \lim _{n \rightarrow \infty} g y_{n+1}=y \text {. }
$$

From the commutativity of $T$ and $g$, we have

$$
g\left(g x_{n+1}\right)=g\left(T\left(x_{n}, y_{n}\right)\right)=T\left(g x_{n}, g y_{n}\right), g\left(g y_{n+1}\right)=g\left(T\left(y_{n}, x_{n}\right)\right)=T\left(g y_{n}, g x_{n}\right) .
$$

Letting $n \rightarrow \infty$ in (2.18) and from the continuity of $T$ and $g$, we get

$$
\begin{aligned}
& g x=\lim _{n \rightarrow \infty} g\left(g x_{n+1}\right)=\lim _{n \rightarrow \infty} T\left(g x_{n}, g y_{n}\right)=T\left(\lim _{n \rightarrow \infty} g x_{n}, \lim _{n \rightarrow \infty} g y_{n}\right)=T(x, y), \\
& g y=\lim _{n \rightarrow \infty} g\left(g y_{n+1}\right)=\lim _{n \rightarrow \infty} T\left(g y_{n}, g x_{n}\right)=T\left(\lim _{n \rightarrow \infty} g y_{n}, \lim _{n \rightarrow \infty} g x_{n}\right)=T(y, x) .
\end{aligned}
$$

This implies that $(x, y)$ is a coupled coincidence point of $T$ and $g$. This completes the proof.

Corollary 2.2 Let $(X, d, \preceq)$ be a partially ordered complete metric space. Suppose there exist $\lambda \in[0,1)$, 
$T: X \times X \rightarrow X$ such that

$$
d(T(x, y), T(u, v)) \leq \lambda \max \left\{\frac{d(x, T(x, y)) \cdot d(u, T(u, v))}{d(x, u)}, \frac{d(u, T(x, y)) \cdot d(x, T(u, v))}{d(x, u)}, d(x, u)\right\},
$$

for all $x, y, u, v \in X$ with $x \preceq u, y \succeq v$ and $x \neq u$. Suppose also that $T$ is continuous, has the mixed monotone property on $X$. If there exist $\left(x_{0}, y_{0}\right) \in X \times X$ such that $x_{0} \preceq T\left(x_{0}, y_{0}\right)$ and $y_{0} \succeq T\left(y_{0}, x_{0}\right)$, then there exist $x, y \in X$ such that $x=T(x, y)$ and $y=T(y, x)$.

Proof. In Theorem 2.1, taking $\psi(t)=t$ and $\phi(t)=(1-\lambda) t$, for all $t \in[0, \infty)$ and $g=I_{X}$, we obtain the corollary 2.2 .

Now we give sufficient conditions for uniqueness of the coupled coincidence point. Note that if $(X, \preceq)$ is a partially ordered set, then we endow the product $X \times X$ with the following partial order relation, for all $(x, y),(z, t) \in X \times X$,

$$
(x, y) \preceq(z, t) \Leftrightarrow x \preceq z, y \succeq t .
$$

From Theorem 2.1, it follows that the set of coupled coincidence points of $T$ and $g$ is non-empty.

Theorem 2.3 By adding to the hypotheses of Theorem 2.1, the condition: for every $(x, y)$ and $(z, t)$ in $X \times X$, there exists a $(u, v) \in X \times X$ such that $(T(u, v), T(v, u))$ is comparable to $(T(x, y), T(y, x))$ and to $(T(z, t), T(t, z))$, then $T$ and $g$ have a unique coupled common fixed point, that is, there exist a unique $(x, y) \in X \times X$ such that

$$
x=g x=T(x, y), y=g y=T(y, x) .
$$

Proof. We know, from Theorem 2.1, that exists a coupled coincidence point. Suppose that $(x, y)$ and $(z, t)$ are coupled coincidence points of $T$ and $g$, that is, $T(x, y)=g x, T(y, x)=g y, T(z, t)=g z$ and $T(t, z)=g t$. We shall show that $g x=g z$ and $g y=g t$. By assumption, there exists $(u, v) \in X \times X \quad$ such that $(T(u, v), T(v, u)) \quad$ is comparable to $(T(x, y), T(y, x))$ and to $(T(z, t), T(t, z))$. Without the restriction to the generality, we can assume that

$$
(T(x, y), T(y, x)) \preceq(T(u, v), T(v, u)) \quad \text { and }(T(z, t), T(t, z)) \preceq(T(u, v), T(v, u)) .
$$


Put $u_{0}=u, v_{0}=v$ and choose $\left(u_{1}, v_{1}\right) \in X \times X$ such that

$$
g u_{1}=T\left(u_{0}, v_{0}\right), g v_{1}=T\left(v_{0}, u_{0}\right)
$$

For $n \geq 1$, continuing this process we can construct the sequences $\left\{g u_{n}\right\}$ and $\left\{g v_{n}\right\}$ such that

$$
g u_{n+1}=T\left(u_{n}, v_{n}\right), g v_{n+1}=T\left(v_{n}, u_{n}\right) \text { for all } n .
$$

Further, set $x_{0}=x, y_{0}=y$ and $z_{0}=z, t_{0}=t$ and on the same way define the sequences $\left\{g x_{n}\right\}$, $\left\{g y_{n}\right\},\left\{g z_{n}\right\}$ and $\left\{g t_{n}\right\}$. Then, it is easy to check that $g x_{n} \rightarrow T(x, y), g y_{n} \rightarrow T(y, x)$ and $g z_{n} \rightarrow T(z, t), g t_{n} \rightarrow T(t, z)$, for all $\mathrm{n} \geq 1$.

Since $(T(x, y), T(y, x))=(g x, g y)=\left(g x_{1}, g y_{1}\right)$ is comparable to $(T(u, v), T(v, u))=\left(g u_{1}, g v_{1}\right)$, then it is easy to show $(g x, g y) \preceq\left(g u_{n}, g v_{n}\right)$, that is, $g x \preceq g u_{n}$ and $g y \succeq g v_{n}$ for all $n \in \mathbb{N}$.

Thus from (2.1), we have

$$
\psi\left(d\left(g x, g u_{n+1}\right)\right)=\psi\left(d\left(T(x, y), T\left(u_{n}, v_{n}\right)\right)\right) \leq \psi\left(M\left(x, y, u_{n}, v_{n}\right)\right)-\phi\left(M\left(x, y, u_{n}, v_{n}\right)\right),
$$

where

$$
\begin{aligned}
M\left(x, y, u_{n}, v_{n}\right) & =\max \left\{\frac{d(g x, T(x, y)) \cdot d\left(g u_{n}, T\left(u_{n}, v_{n}\right)\right)}{d\left(g x, g u_{n}\right)}, \frac{d\left(g u_{n}, T(x, y)\right) \cdot d\left(g x, T\left(u_{n}, v_{n}\right)\right)}{d\left(g x, g u_{n}\right)}, d\left(g x, g u_{n}\right)\right\} \\
& =\max \left\{\frac{d(g x, g x) \cdot d\left(g u_{n}, g u_{n+1}\right)}{d\left(g x, g u_{n}\right)}, \frac{d\left(g u_{n}, g x\right) \cdot d\left(g x, g u_{n+1}\right)}{d\left(g x, g u_{n}\right)}, d\left(g x, g u_{n}\right)\right\} \\
& =\max \left\{d\left(g x, g u_{n+1}\right), d\left(g x, g u_{n}\right)\right\} .
\end{aligned}
$$

Hence

$\psi\left(d\left(g x, g u_{n+1}\right)\right) \leq \psi\left(\max \left\{d\left(g x, g u_{n+1}\right), d\left(g x, g u_{n}\right)\right\}\right)-\phi\left(\max \left\{d\left(g x, g u_{n+1}\right), d\left(g x, g u_{n}\right)\right\}\right)$.

It is easy to show that

$$
\psi\left(d\left(g x, g u_{n+1}\right)\right) \leq \psi\left(d\left(g x, g u_{n}\right)\right)-\phi\left(d\left(g x, g u_{n}\right)\right)<\psi\left(d\left(g x, g u_{n}\right)\right) .
$$

This implies that $\left\{d\left(g x, g u_{n}\right)\right\}$ is a non-increasing sequence. Hence, there exists $r \geq 0$ such that

$$
\lim _{n \rightarrow \infty} d\left(g x, g u_{n}\right)=r
$$

Passing the upper limit in (2.20) as $n \rightarrow \infty$, we obtain

$$
\psi(r) \leq \psi(r)-\phi(r)
$$

which implies that $\phi(r)=0$ and then, $r=0$. We deduce that 


$$
\lim _{n \rightarrow \infty} d\left(g x, g u_{n}\right)=0 .
$$

Similarly one can prove that

$$
\lim _{n \rightarrow \infty} d\left(g y, g v_{n}\right)=0 .
$$

Similarly, one can prove that

$$
\lim _{n \rightarrow \infty} d\left(g z, g u_{n}\right)=\lim _{n \rightarrow \infty} d\left(g t, g v_{n}\right)=0 .
$$

By the triangle inequality, (2.22) and (2.23), we get

$$
\begin{aligned}
& d(g x, g z) \leq d\left(g x, g u_{n+1}\right)+d\left(g z, g u_{n+1}\right) \rightarrow 0 \text { as } n \rightarrow \infty, \\
& d(g y, g t) \leq d\left(g y, g v_{n+1}\right)+d\left(g t, g v_{n+1}\right) \rightarrow 0 \text { as } n \rightarrow \infty .
\end{aligned}
$$

Therefore, we have $g x=g z$ and $g y=g t$. Since $g x=T(x, y)$ and $g y=T(y, x)$, by commutativity of $T$ and $g$, we have

$$
g(g x)=g(T(x, y))=T(g x, g y), g(g y)=g(T(y, x))=T(g y, g x) .
$$

Denote $g x=a$ and $g y=b$. Then from (2.24),

$$
g(a)=T(a, b), g(b)=T(b, a) .
$$

Thus, $(a, b)$ is a coupled coincidence point, it follows that $g a=g z$ and $g b=g y$, that is, $g(a)=a, g(b)=b$.

From (2.25) and (2.26),

$$
a=g(a)=T(a, b), b=g(b)=T(b, a) .
$$

Therefore, $(a, b)$ is a coupled common fixed point of $T$ and $g$. To prove the uniqueness of the point $(a, b)$, assume that $(c, d)$ is another coupled common fixed point of $T$ and $g$. Then we have

$$
c=g c=T(c, d), d=g d=T(d, c) .
$$

Since $(c, d)$ is a coupled coincidence point of $T$ and $g$, we have $g c=g x=a$ and $g d=g y=b$. Thus $c=g c=g a=a$ and $d=g d=g b=b$. Hence, the coupled common fixed point is unique. This completes the proof.

Theorem 2.4 In addition to hypotheses of Theorem 2.3, if $g x_{0}$ and $g y_{0}$ are comparable, then $T$ and $g$ 
have a unique common fixed point, that is, there exists $x \in X$ such that $x=g x=T(x, x)$.

Proof. By Theorem 2.1, we can construct two sequences $\left\{g x_{n}\right\}$ and $\left\{g y_{n}\right\}$ in $\mathrm{X}$ such that $g x_{n} \rightarrow x$ and $g y_{n} \rightarrow y$, where $(x, y)$ is a unique coupled common fixed point of $T$ and $g$. We only have to show that $x=y$. Since $g x_{0}$ and $g y_{0}$ are comparable, we may assume that $g x_{0} \preceq g y_{0}$, then it is an easy matter to show that

$$
g x_{n} \preceq g y_{n} \text { for all } n \geq 0 \text {. }
$$

From (2.1) and (2.28), we have

$$
\psi\left(d\left(g x_{n+1}, g y_{n+1}\right)\right)=\psi\left(d\left(T\left(x_{n}, y_{n}\right), T\left(y_{n}, x_{n}\right)\right)\right) \leq \psi\left(M\left(x_{n}, y_{n}, y_{n}, x_{n}\right)\right)-\phi\left(M\left(x_{n}, y_{n}, y_{n}, x_{n}\right)\right)
$$

where

$$
\begin{aligned}
M\left(x_{n}, y_{n}, y_{n}, x_{n}\right) & =\max \left\{\frac{d\left(g x_{n}, T\left(x_{n}, y_{n}\right)\right) \cdot d\left(g y_{n}, T\left(y_{n}, x_{n}\right)\right)}{d\left(g x_{n}, g y_{n}\right)}, \frac{d\left(g y_{n}, T\left(x_{n}, y_{n}\right)\right) \cdot d\left(g x_{n}, T\left(y_{n}, x_{n}\right)\right)}{d\left(g x_{n}, g y_{n}\right)},\right. \\
& \left.d\left(g x_{n}, g y_{n}\right)\right\} \\
= & \max \left\{\frac{d\left(g x_{n}, g x_{n+1}\right) \cdot d\left(g y_{n}, g y_{n+1}\right)}{d\left(g x_{n}, g y_{n}\right)}, \frac{d\left(g y_{n}, g x_{n+1}\right) \cdot d\left(g x_{n}, g y_{n+1}\right)}{d\left(g x_{n}, g y_{n}\right)}, d\left(g x_{n}, g y_{n}\right)\right\} .
\end{aligned}
$$

By taking the upper limit as $n \rightarrow \infty$, we get

$$
\lim _{n \rightarrow \infty} M\left(x_{n}, y_{n}, y_{n}, x_{n}\right)=d(x, y) .
$$

Hence

$$
\psi(d(x, y)) \leq \psi(d(x, y))-\phi(d(x, y))
$$

which implies that $\phi(d(x, y))=0$. Therefore $x=y$, that is, $T$ and $g$ have a common fixed point.

Similar arguments can be used if $g x_{0} \succeq g y_{0},$.

\section{References}

[1] Aydi, H, Karapinar,E, Shatanawi,W: Coupled fixed point results for $(\psi-\varphi)-$ weakly contractive condition in ordered partial metric spaces. Comput. Math. Appl. 62, 4449-4460 (2011).

[2] Banach,S: Surles operations dans les ensembles et leur application aux equation sitegrales. Fund. Math.3, 133-181 (1922).

[3] Bhaskar,TG, Lakshmikantham ,V: Fixed point theory in partially ordered metric spaces and applications. Nonlinear Anal.65, 1379-1393 (2006).

[4] Bhardwaj,R: Coupled fixed point theorems in partially ordered metric space. Mathematical theory and modeling.Vol.2, No.4, 2012.

[5] Choudhury,BS, Kundu,A: A coupled coincidence point result in partially ordered metric spaces for compatible mappings. Nonlinear Anal. 73, 2524 - 2531 (2010). doi:10.1016/j.na.2010.06.025 
[6] Choudhury,BS, Metiya,N, Kundu,A: Coupled coincidence point theorems in ordered metric spaces. Ann. Univ. Ferrara 57, 1-16 (2011).

[7] Lakshmikantham,V, $C^{\prime}$ irifi $c^{\prime}, \mathrm{L}$ : Coupled fixed point theorems for nonlinear contractions in partially ordered metric spaces. Nonlinear Anal: Theorey Methods Appl.70(12), $4341 \quad$-4349 (2009). doi:10.1016/j.na.2008.09.020.

[8] Luong,NV, Thuan,NX: Coupled fixed point theorems in partially ordered metric spaces. Bul. Math. An. Appl., 4(2010), 16-24.

[9] Singh.SL, Prasad,B: Some coincidence theorems and stability of iterative proceders, Comput. Math. Appl., 55 (2008) 2512-2520.

[10] Shatanawi,W: Fixed point theorems for nonlinear weakly $C$-contractive mappings in metric spaces. Math. Comput. Model. 54, 2816-2826 (2011).

[11]Shatanawi,W, Mustafa,Z, Tahat,N: Some coincidence point theorems for nonlinear contraction in ordered metric spaces. Fixed Point Theory Appl.2011, 68 (2011). 